\title{
COMPLETE HEART BLOCK TREATED WITH CORTICOTROPHIN AND CORTICOSTEROID
}

\author{
BY \\ CLIVE P. ABER AND E. WYN JONES \\ From the Liverpool Royal Infirmary and the Liverpool Regional Cardiac Centre \\ Received May 14, 1960
}

In 1954 Prinzmetal and Kennamer first described the successful use of corticotrophin in a case of acute myocardial infarction with complete heart block and severe Adams-Stokes attacks, which had proved resistant to the conventional forms of therapy. A further report (Phelps and Lindsay 1957) also suggested the possible value of cortisone in this type of case, and recently Gilchrist (1960) mentions the use of corticosteroids for complete heart block following acute myocardial infarction. In other forms of heart disease where complete heart block and Adams-Stokes attacks were prominent, both corticotrophin and corticosteroids have bəen used with some success in endeavours to abolish the conduction block (Tung et al., 1957: Litchfield et al., 1958), and many physicians will now be familiar with the resolution of arrhythmias and varying degrees of heart block when corticosteroids have been given to patients with acute rheumatic carditis.

The rationale of this form of treatment is that heart block may be due to a reversible inflammatory reaction in the region of the atrio-ventricular node and bundle of His, rather than to permanent damage at this site, and that it may be possible to suppress this reaction and abolish the block with these anti-inflammatory drugs. Furthermore Lown et al. (1955), in a study of patients with either Addison's disease or Cushing's disease and of the effects of cortisone on normal subjects, found evidence that adrenal corticosteroids have a direct accelerator effect on atrio-ventricular conduction.

Prior to using these potentially dangerous drugs in patients with myocardial infarction and other forms of heart disease, it is of the utmost importance to know their effects on the already damaged myocardium. In this respect it has been shown that in active rheumatic carditis (Joint Trial, 1955; Illingworth et al., 1957), considerable benefit has been derived from this type of therapy, while in experimentally induced myocardial infarction in laboratory animals cortisone seems to exert no detrimental effects on the healing process (Chapman et al., 1952; Opdyke et al., 1953; and Hepper et al., 1955).

In the following five cases, four of complete heart block and one of A-V dissociation, corticotrophin (ACTH gel) or corticosteroids (ledercort) or both have been used in attempts to abolish the respective arrhythmias.

\section{CASE REPORTS}

Case 1. A woman, aged 71 years, suddenly lost consciousness in the street. On admission she had completely recovered her faculties and gave no history of previous heart trouble nor had she ever experienced ischæmic cardiac pain.

On examination the pulse was regular at a rate of 44 a minute. Her blood pressure was 180/80. Clinically and radiologically there was considerable generalized cardiomegaly, but no signs of valvular disease were detected. She had complete atrio-ventricular block with a right bundle branch block (Fig. 1a). Serum transaminase levels taken 4 hours and 24 hours after her blackout were 100 and 300 units respectively. Serum cholesterol was $240 \mathrm{mg}$., serum urea $25 \mathrm{mg}$. each per $100 \mathrm{ml}$. Serum electrolytes were sodium 140 m.eq./l., potassium 4 m.eq./l., and chloride 98 m.eq./l. Her W. R. was negative. 
After two further and rather prolonged blackouts within 26 hours of admission to hospital corticotrophin therapy (ACTH gel 40 units b.i.d.) was started and the next day sinus rhythm was restored, now with the associated changes of a left bundle-branch block (Fig. 1b.). She remained well and the cardiographic pattern was maintained (as Fig. 1b) despite gradual withdrawal from corticotrophin and substitution of ledercort (4 mg. t.i.d.) as maintenance therapy for three months, after which all treatment was discontinued. When last seen a month later she had had no further Adams-Stokes attacks and the cardiogram at this stage was unchanged (Fig. 1c).

Comment. There seemed no doubt that this patient had had an episode of acute myocardial damage situated near the A-V node and bundle of His. The age of the patient and the serum transaminase levels

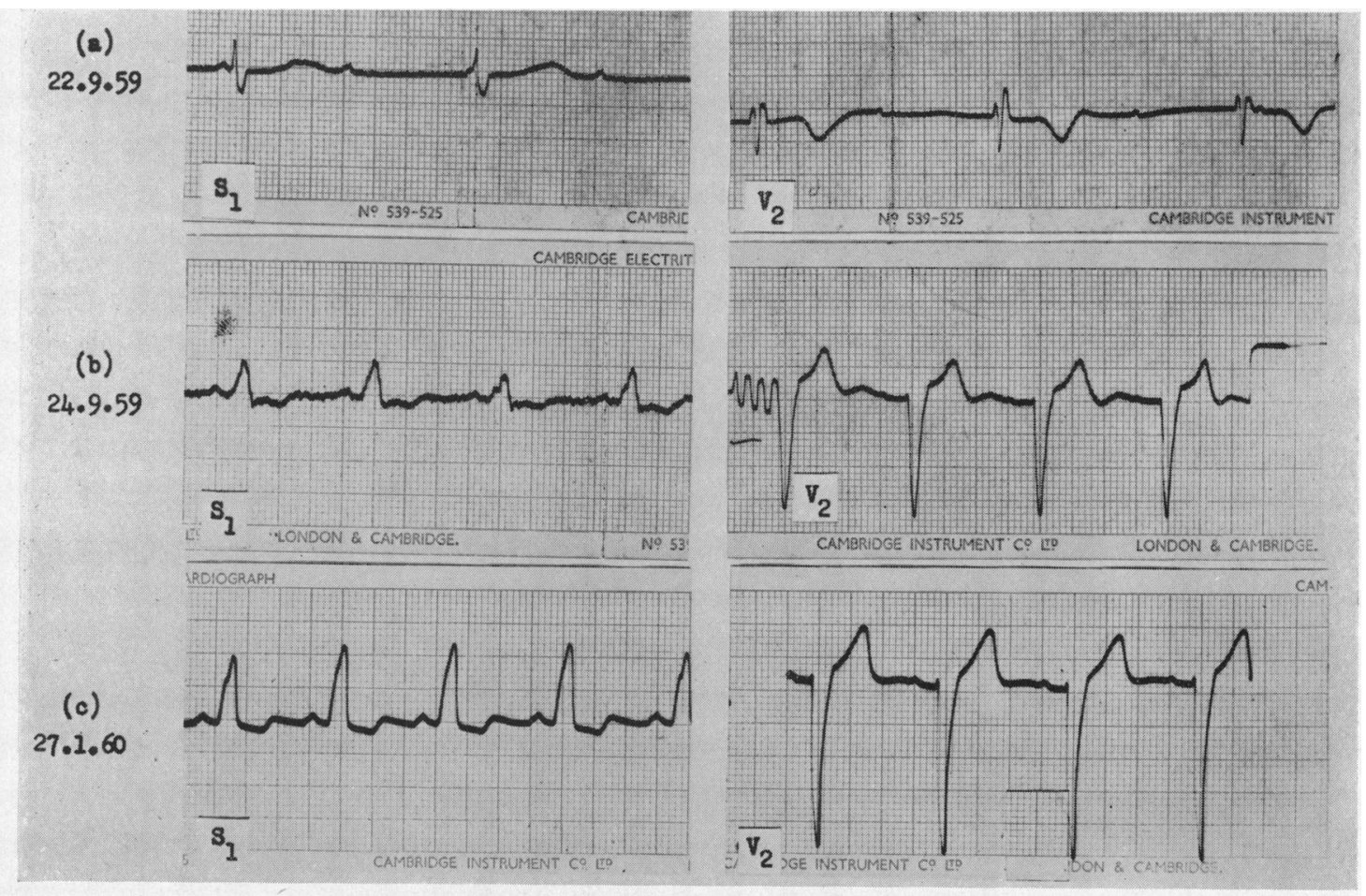

FIG. 1.-(a) Complete heart block with right bundle-branch block. (b) and (c) Sinus rhythm with left bundle-branch block.

suggested that this was probably the result of an acute painless myocardial infarction. Her improvement, the abolition of the complete heart block, and the bundle-branch block pattern changing, while on corticotrophin therapy, also suggested that this treatment may have suppressed an inflammatory reaction of the myocardium at this critical site, at the critical stage in her illness.

Case 2. A woman, aged 67, was first observed to have Adams-Stokes attacks in December 1955. Unfortunately no electrocardiogram was taken at this time but clinical examination had revealed a pulse rate of 40 a minute, a blood pressure of $200 / 100$, no evidence of valvular heart disease, but some cardiomegaly. There was no history of ischæmic heart pain. In April 1956 she had been free of further Adams-Stokes attacks for four months and a cardiogram then revealed 2:1 A-V block (Fig. 2a). On maintenance ephedrine (grains $\frac{1}{2}$, b.i.d.) she remained well until September 1959, when the attacks returned with alarming frequency and on admission (2/9/59) the pulse was regular at a rate of 36 a minute and the B.P. 170/60. There was now complete heart block (Fig. 2b).

Serum transaminase, 90 units: serum cholesterol $180 \mathrm{mg}$., serum urea $45 \mathrm{mg}$., each per $100 \mathrm{ml}$.: serum 
electrolytes; sodium 136 m.eq./l., potassium 4.2 m.eq./l., chloride 97 m.eq./l., W. R. negative. X-ray chest, marked left ventricular enlargement.

We thought it possible that she had had a recent episode of ischæmic myocardial damage and corticotrophin therapy (ACTH gel. 40 units b.i.d.) was started at once. No further Adams-Stokes attacks occurred from the commencement of treatment although the pulse rate remained unchanged for 17 days when it rose slightly and there was $2: 1 \mathrm{~A}-\mathrm{V}$ block (Fig. 2c). Corticotrophin therapy was then gradually withdrawn and she remained free of further Adams-Stokes attacks and there were no further changes in the cardiogram, until her sudden death at home on 6/12/59. No autopsy was performed.

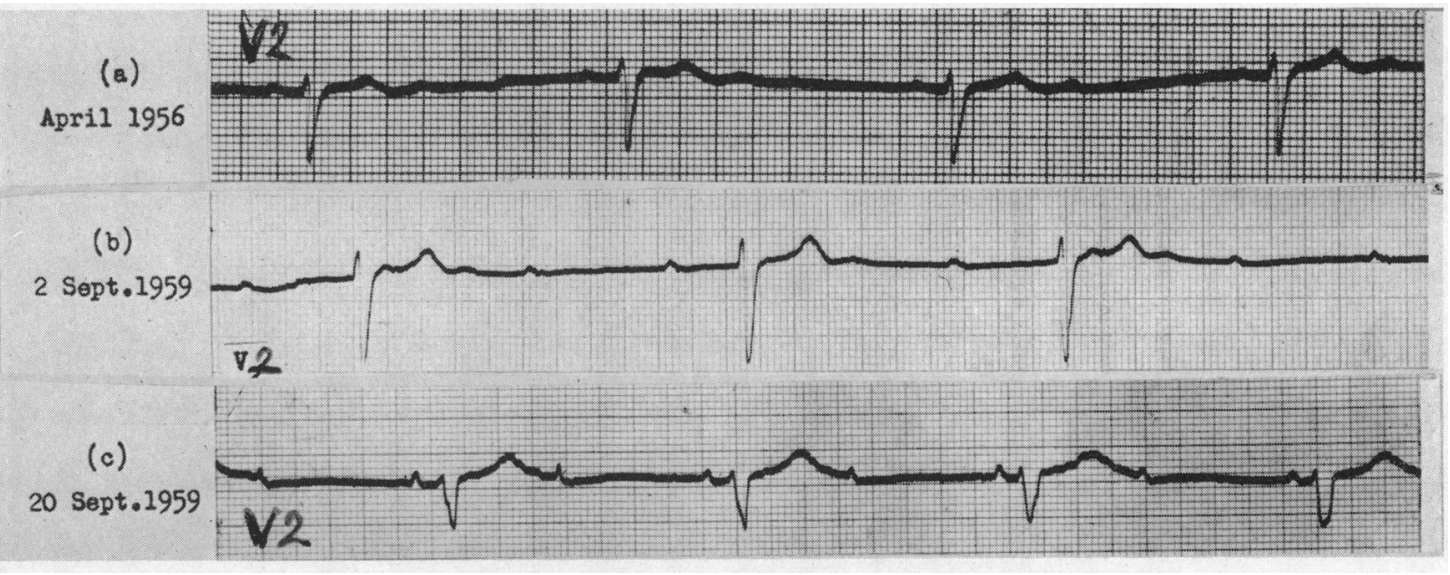

Fig. 2.-(a) 2:1 A-V block. (b) Complete heart block. (c) 2:1 A-V block.

Comment. This patient undoubtedly improved after starting corticotrophin therapy, despite no immediate changes in her heart rhythm or pulse rate. Her clinical progress and the later re-appearance of 2:1 A-V block, for the first time for three years, may well have been due to this form of treatment.

Case 3. A man, aged 39 years, began to have Adams-Stokes attacks in October 1958. At this time there was no evidence of valvular heart disease, coronary artery disease, or collagenosis, and a cardiogram taken with the patient free of symptoms revealed complete heart block (Fig. 3a).

The attacks continued despite conventional therapy until April 1959 when a further record (again taken between attacks) was normal (Fig. 3b). He refused admission to hospital and remained well until November 1959 without treatment. The attacks then returned with frightening frequency and he was admitted. During a subsequent series of severe Adams-Stokes attacks his pulse rate fell to 26-30 a minute for periods of one to three minutes, and a cardiogram (13/11/59) taken at this time showed a varying A-V block (Fig. 3c).

Corticotrophin therapy (ACTH gel 40 units a day) was then started and within six hours of the first injection the blackouts ceased and the pulse rate rose to 100 a minute (Fig. 3d). He remained free of further trouble for a week when following a reduction of the dose of ACTH gel to 30 units a day he had several further Adams-Stokes attacks which promptly responded to increasing the dose of ACTH to 40 units a day.

Subsequently the corticotrophin was once again gradually reduced to 10 units on alternate days and ledercort was introduced (4 mg. t.i.d.) as maintenance therapy. No more attacks occurred until 25/1/60 when again a further reduction of the dose of ACTH was followed by reappearance of transient episodes of heart block on the days on which he received no therapy. When once again established on a higher dose of ACTH (with ledercort $4 \mathrm{mg}$. t.i.d.) he improved and has maintained this improvement for another three weeks.

Comment. The reason for this patient's myocardial trouble was not established. He certainly obtained considerable benefit from corticotrophin and ledercort therapy and demonstrated his dependence on a critical dose of ACTH in order to maintain this improvement. This was noted by Litchfield et al. (1958) also in a similar case.

Case 4. A woman, aged 55, was admitted to hospital with a six months' history of irregular fluttering of 


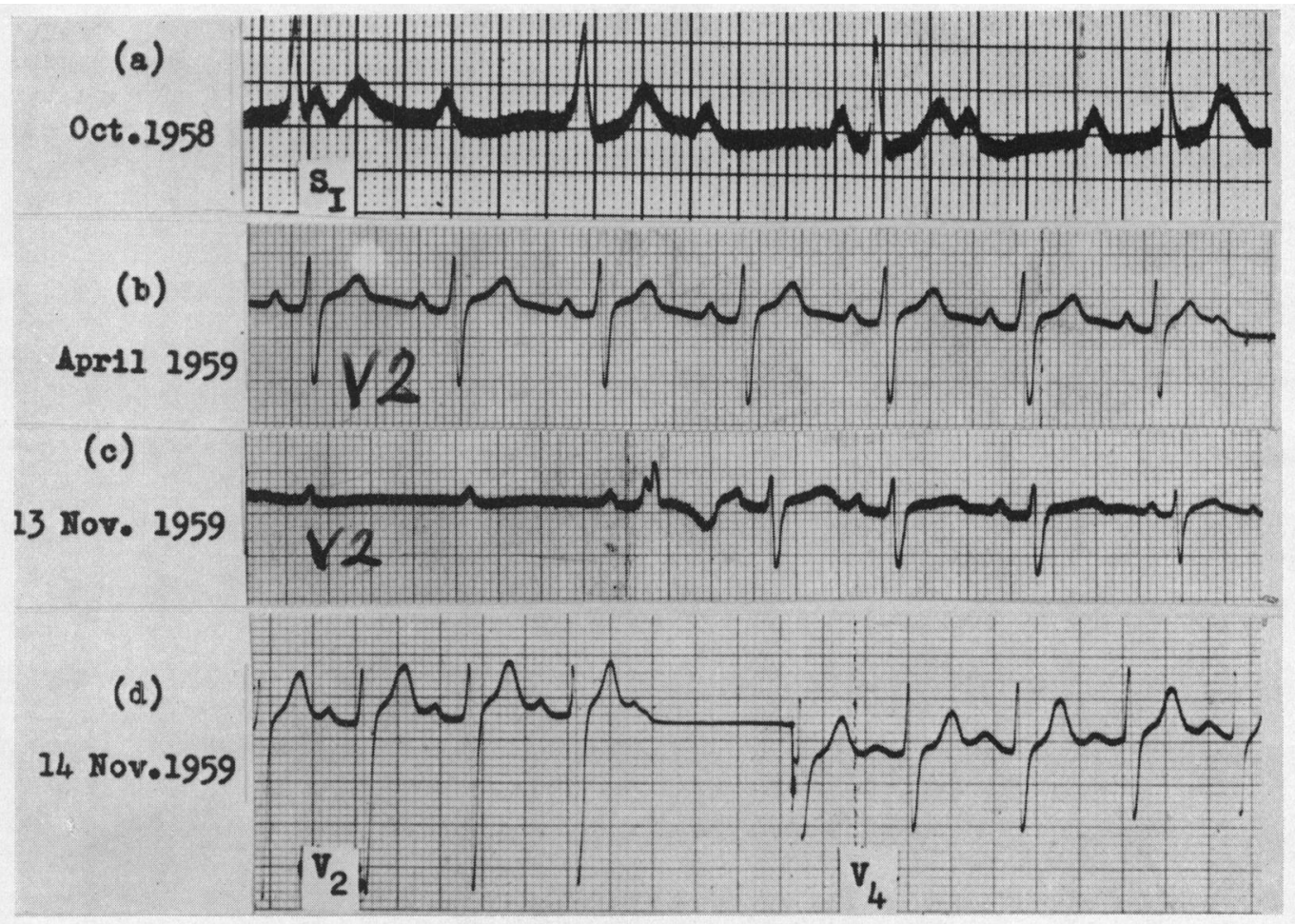

Fig. 3.-(a) Complete heart block. (b) Sinus rhythm. (c) Shows the termination of a period of complete ventricular standstill. (d) Sinus rhythm restored.

the heart; breathlessness on exertion, and three attacks of unconsciousness which were thought to have been Adams-Stokes attacks. There was only a very doubtful history of ischæmic heart pain.

On examination (18/6/59) the pulse was irregular at a rate of $36-40$ a minute, the heart was enlarged but there was no clinical evidence of valvular heart disease. B.P. 140/80. She showed 4:1 A-V block with right bundle-branch block (Fig. 4a), whereas 12 hours later complete heart block was evident (Fig. 4b). $\mathrm{X}$-ray of the chest showed generalized cardiomegaly and some pulmonary congestion.

Serum transaminase, 40 units; serum proteins; total $7 \cdot 4$ g., albumin $4 \cdot 1$ g., globulin $3.3 \mathrm{~g}$., each per $100 \mathrm{ml}$. $(\gamma$ globulin $0.8 \mathrm{~g}$.); serum cholesterol $140 \mathrm{mg}$., serum urea $40 \mathrm{mg}$. each per $100 \mathrm{ml}$. Serum electrolytes were sodium 138 m.eq./l., potassium 4.2 m.eq./l., and chloride 98 m.eq./l. No L.E. cells were seen in the peripheral blood.

Despite conventional treatment the attacks of unconsciousness persisted with varying severity: at times periods of ventricular asystole lasted up to 60 seconds and were succeeded on occasions by short bursts of tachycardia (Fig. 4c). By 1/7/59 she was critically ill in congestive heart failure and it was then observed that the serum potassium level was only $2.3 \mathrm{~m}$. eq./1. Corticotrophin therapy was started (ACTH gel 40 units b.i.d.) along with the administration of oral potassium chloride $(1 \mathrm{~g}$. t.i.d.). Within ten hours she felt much better and the record showed 4:1 A-V block with a right bundle-branch block (with disappearance of the ventricular extrasystoles). On 4/7/59 there was 2:1 A-V block (Fig. 4d) and by 7/7/59 sinus rhythm had returned with persistence of the right bundle-branch block (Fig. 4e). The serum potassium at this point was 3.5 m.eq./l. Following gradual reduction of the dose of ACTH, 2:1 A-V block returned (13/7/59) and despite further increases in the dose of ACTH to 40 units b.i.d. this block persisted.

Her subsequent progress was punctuated by a further episode of congestive heart failure, a severe chest infection, and several more Adams-Stokes attacks with varying degrees of heart block, which proved resistant to treatment with cortisone, sodium lactate, calcium gluconate, ephedrine, adrenaline, and atropine. When last seen (6/2/60) there was 2:1 A-V block with right bundle-branch block (Fig. 4f) and she has been almost free from Adams-Stokes attacks for three months. 
Comment. In this case the exact nature of the myocardial damage was not clear, but there seems no doubt that her deterioration on 1/7/59 was in part due to the development of hypokalæmia. Her improvement on corticotrophin therapy and potassium chloride (orally) was, we feel, too rapid to be explained entirely on a rising serum potassium and it seems possible that the corticotrophin promoted the transient restoration of sinus rhythm that enabled her to survive.

Case 5. A woman, aged 55, had enjoyed good health until November 1959 when she began to experience "a few thumps in the chest" in association with a peculiar feeling in the pit of the stomach. In retrospect she remembered that there had been some doubt about her "heart action" 20 years ago when her only child was born. There was no history of exertional chest pain or of anything to suggest a recent episode of ischæmic heart damage.

On examination $(9 / 12 / 59)$ pulse rate 80 a minute, B.P. $160 / 90$. No evidence of valvular heart disease. $\mathrm{X}$-ray of chest and screening of heart, normal. Complete A-V dissociation but no other abnormality (Fig. 5a).

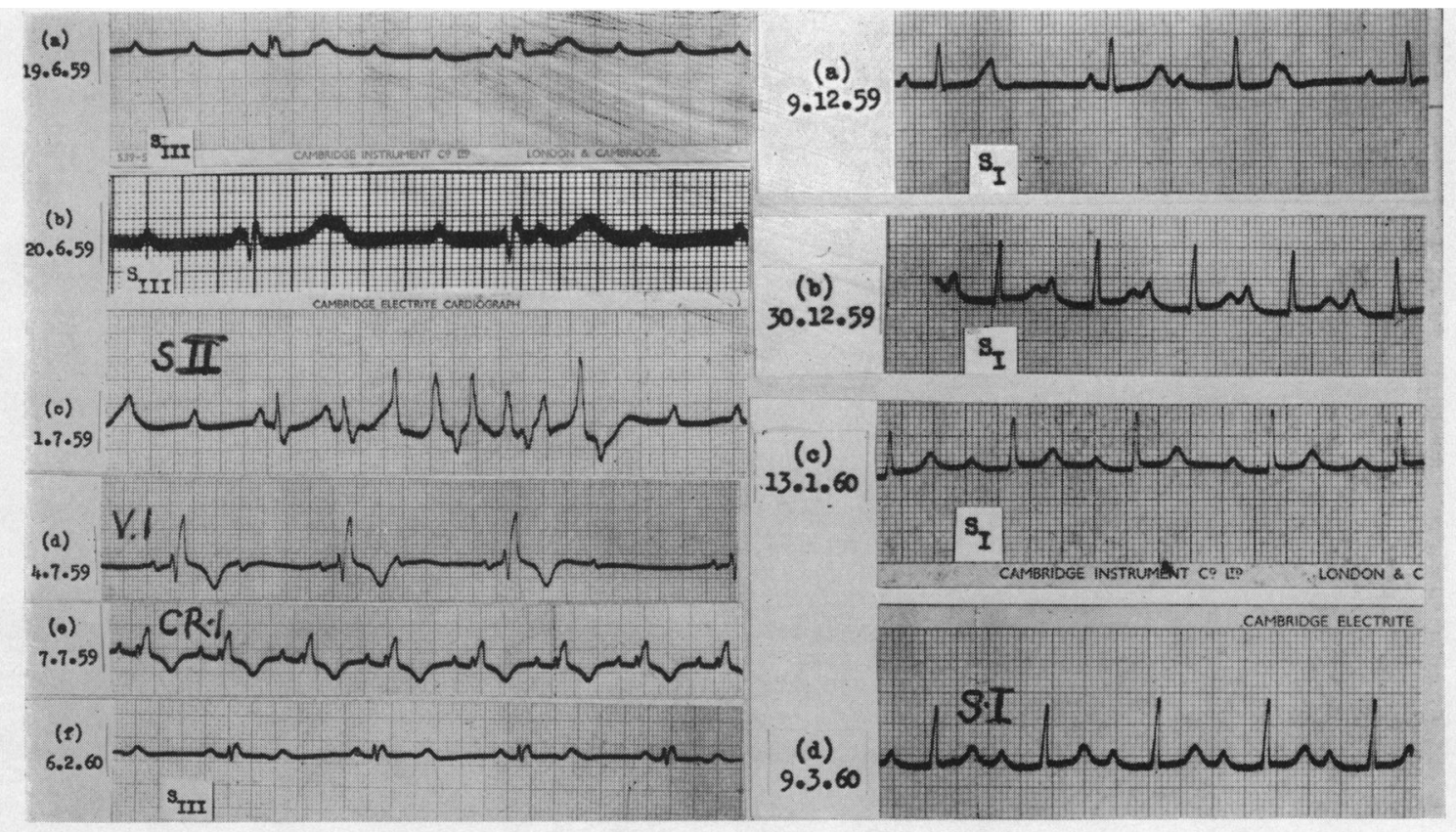

FIG. 4.-(a) 4:1 A-V block with right bundle-branch block. (b) Complete heart block. (c) Ventricular asystole succeeded by a short bout of ventricular extrasystoles. (d) $2: 1$ A-V block with right bundle-branch block. (e) Sinus rhythm with right bundle-branch block. (f) 2:1 A-V block with right bundle-branch block.

FIG. 5.-(a) Complete A-V dissociation. (b) Sinus rhythm with prolongation of the $\mathbf{P}-\mathbf{R}$ interval ( $0 \cdot 28$ sec.). (c) and $(d)$ Sinus rhythm with a slightly shorter P-R interval $(0.26 \mathrm{sec}$.)

Ledercort therapy ( 4 mg. t.i.d.) was started at once and by 30/12/59 the pulse rate had risen to 100 a minute and a further record showed sinus rhythm with prolongation of the $P-R$ interval to $0.28 \mathrm{sec}$. (Fig. $5 \mathrm{~b}$ ). She remained well and two weeks later still showed sinus rhythm with, however, a somewhat shorter P-R interval of $0.26 \mathrm{sec}$. (Fig. 5c). Over the next eight weeks the dose of ledercort was gradually reduced to $2 \mathrm{mg}$. daily and when last seen two months later she was still well, but there remained some prolongation of the P-R interval (Fig. 5d).

Comment. Here again the ætiology of the heart damage and arrhythmia was uncertain, but the disappearance of the A-V dissociation after starting corticosteroid therapy and the persistence of the prolonged P-R interval suggests that there may well have been resolution of some of the myocardial damage while on this form of therapy. 


\section{DiscUSSION}

The above observations are open to alternative interpretations as the natural course of complete heart block and other cardiac arrhythmias is so variable (Penton et al., 1956), and no firm conclusions can be drawn from such a small series of cases of diverse ætiology. However, it would seem that this form of therapy may be valuable in overcoming persistent complete heart block when it is causing incapacitating Adams-Stokes attacks that have proved resistant to the more conventional therapeutic measures. Furthermore, it might even be the treatment of choice in those desperate cases of complete heart block occurring after a recent myocardial infarction or with severe myocardial damage whatever its ætiology, where the prognosis is most uncertain and often grave (Penton et al., 1956; Gilchrist, 1960). Whether or not such a therapeutic regime should be tried in circumstances where acute complete heart block is asymptomatic or where any acute arrhythmia develops remains speculative, but our experience with Case 5 suggests that this is worth consideration, particularly in view of the absence so far of serious side effects from the use of corticosteroids or corticotrophin in this type of case.

\section{SUMMARY}

A report on the use of corticotrophin and corticosteroids in an attempt to abolish the conduction block, in four cases of complete heart block and one case of A-V dissociation, has been presented.

We should like to thank Dr. Baker-Bates for the invitation to see Case 4 and for permitting us to use his records; and also Dr. A. John Robertson for allowing us to publish Case 5.

\section{REFERENCES}

Chapman, D. W., Skaggs, R. H., Thomas, J. R., and Greene, J. A. (1952). Amer. J. med. Sci., $223,41$.

Gilchrist, A. R. (1960). Brit. med. J., 1, 215.

Hepper, N. G., Proutt, R. D., Donald, D. E., and Edwards, J. E. (1955). Circulation, 11, 742.

Illingworth, R. S., Lorber, J., Holt, K. S., Rendle-Scott, J., Jowett, G. H., and Gibson, W. (1957). Lancet, $2,653$.

Litchfield, J. W., Mawley, K. A., and Polak, A. (1958). Lancet, 1, 935.

Lown, B., Arons, W. L., Ganong, W. F., Vazifdar, J. P., and Levine, S. A., (1955). Amer. Heart J., $50,760$.

Opdyke, D. F., Lambert, A., Stoerk, H. C., Zanetti, M. E., and Kuna, M. A. (1953). Circulation, 8, 544.

Penton, G. B., Miller, H., and Levine, S. A. (1956). Circulation, 13, 801.

Phelps, M. D., Jr., and Lindsay, J. D., Jr. (1957). New Eng. J. Med., 256, 204.

Prinzmetal, M. and Kennamer, R. (1954). J. Amer. med. Ass., 154, 1049.

Tung, C. L., Lu, S. T., and Fu, H. H. (1957). Chin. med. J., 75, 181.

United States-United Kingdom Cooperative Council Trial of ACTH, Cortisone, and Aspirin (1955). Brit. med. J., 1, 555. 